\title{
Tibet: Some Inconvenient Truths
}

Tibetan Experts Provide Answers to 100 Chinese Questions on Tibet

Françoise Robin

\section{(2) OpenEdition}

\section{Journals}

Electronic version

URL: http://journals.openedition.org/chinaperspectives/3443

DOI: $10.4000 /$ chinaperspectives.3443

ISSN: 1996-4617

\section{Publisher}

Centre d'étude français sur la Chine contemporaine

\section{Printed version}

Date of publication: 1 January 2008

Number of pages: 98-103

ISSN: 2070-3449

\section{Electronic reference}

Françoise Robin, «Tibet: Some Inconvenient Truths », China Perspectives [Online], 2008/1 | 2008,

Online since 01 January 2011, connection on 24 September 2020. URL : http://

journals.openedition.org/chinaperspectives/3443; DOI : https://doi.org/10.4000/chinaperspectives.

3443

(c) All rights reserved 
C

Tibet: Some

\title{
Inconvenient Truths
}

\author{
Tibetan Experts Provide Answers to 100 Chinese Questions on Tibet
}

\author{
FRANÇOISE ROBIN
}

1 uthenticating Tibet appears at just the right time to provide Western readers with the necessary tools for understanding the crisis that has been shaking the entire Tibetan cultural space within China since March 2008.

Edited by A.-M. Blondeau and K. Buffetrille, two researchers at the Ecole Pratique des Hautes Etudes in Paris, this work first appeared in French in 2002 under the title Le Tibet est-il chinois? Réponses à cent questions chinoises (Albin Michel, 2002). In it, scholars of Tibetan studies offered responses to the questions and answers contained in an official Chinese propaganda pamphlet, Tibet, 100 questions and answers (a French version of which appeared in 1988, a year before its English-language counterpart). This little book, which was circulated widely to Chinese Embassies and the public at large, allowed the Chinese authorities to offer their own view of the history of SinoTibetan relations and Tibet's development since 1950, and particularly targeted Western tourists who follow the Tibetan situation with great interest and often sympathetic concern. Lhasa had witnessed regular outbreaks of unrest since September 1987. In view of the space given to these events, one might think that the authorities considered this pamphlet necessary to brighten their image, tarnished by the riots that had been harshly repressed and that ended in March 1989 with the imposition of marshal law in Lhasa (lifted in May 1990). In 2001, one year prior to the French publication of these "responses to the questions and answers," the Chinese authorities issued a second, updated edition of the white paper, with numerous changes made to the 1989 edition. It was, however, too late to amend Le Tibet est-il chinois?, which was already about to go to print. Astonishingly, the work hardly attracted the attention it deserved, despite the scientific rigour of its articles; admittedly, Tibet was not in the spotlight in 2002 as it is today. Two years ago, the University of California Press decided to undertake an English translation of this work, and its publication now is a good indication of its interest for an interna- tional readership; it is also, hopefully, a recognition of its qualities. These arguments might not in themselves justify a critical review in these pages, however. The crucial interest of this work in English lies in the fact that it takes account of the changes (additions and deletions of questions, reworking of the overall structure) that distinguished the second white paper from the 1989 version. This enables it to gauge the changing priorities of the Chinese government with regard to the question of Tibet. Above all, in the areas dealing with current affairs and which are of vital importance for Tibet, such as demography, the economy, and rapid changes in political direction, the English version of Blondeau and Buffetrille's work sets itself apart through its significant updates and original contributions, not least of which is that of A. M. Fischer (London School of Economics). For several years now Fischer has been recognised as the leading commentator on Tibet's economy, thanks to his very careful and novel reading of the many statistics provided by the Chinese government. Until quite

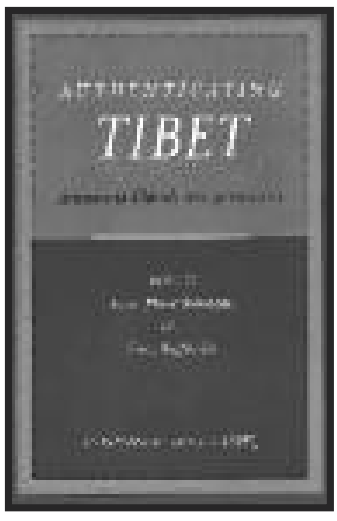

Anne-Marie

Blondeau, Katia

Buffetrille (eds), Authenticating Tibet: Answers to China's 100 Questions, Berkeley, UC Press, 2008, $364 \mathrm{pp}$. recently, this rich but daunting materi-

al had been very little explored by the community of scholars working on Tibet, and never with such attention to detail. Whilst this work might not necessarily give readers definitive answers to the complex questions about Tibet and SinoTibetan relations raised by current events, the well-documented information it provides will at least enable them to bolster their knowledge and think about the subject based on precise data, often backed up by statistics. Thus, in the first part, devoted to "Historical Facts" with contributions by 
A. Chayet and S. Karmay (CNRS), P. Kvaerne (University of Oslo), J. Panglung and H. Uebach (Bavarian Academy of Science and the Humanities), T. Shakya (University of British Columbia), and E. Sperling (University of Indiana), we learn that the Yuanshi, the dynastic history written one year after the fall of the Yuan (Mongol) empire in 1368, did not include Tibet in its chapters devoted to the extent of the empire's land mass (p. 13). The bold Chinese claim that Tibet has indisputably belonged to China since the thirteenth century (the beginning of the Mongol dynasty) is therefore turned on its head. The complex history of relations between Tibet (or rather, various acceptations of the word "Tibet") and the neighbouring empire, whether Mongol (Yuan, 1267-1368), Han (Ming, 1368-1644), or Manchu (Qing, 1644-1911), is spelled out here in detail that takes up nearly one quarter of the book. The period characterised by the Tibetan government as allowing "de facto independence" for Tibet also gains from the eye cast by historians and anthropologists, showing to what extent the Tibet of the Dalai Lamas was at loggerheads with China over its actual status right from the end of the nineteenth century. These scholars also bring out the repercussions arising from British meddling in SinoTibetan relations (British troops reached Lhasa in 1904), undertaken for strategic and trade interests.

Duplicating the organisation of the Chinese tract, the second part of the book deals with "human rights," another subject that China knows is dear to the hearts of Westerners. The responses here to the questions and answers are essentially the work of R. Barnett (University of Columbia, New York), an expert in contemporary Tibetan politics. The dispute between the Chinese government and the Tibetan government in exile over figures relating to the situation of prisons, including the number of people detained, the number of victims that can be attributed to the invasion or liberation of Tibet by Communist China, as well as judicial practices, individual freedoms, education, and access to medical care, is treated in detail, and highlights a deficit in human rights in Tibet that matches, if not exceeds, that in China itself. The measured responses offered by Barnett demonstrate, however, that he adopts a critical stance towards the rhetoric of Dharamsala as much as he does towards the figures and formulations put forward by China. Thus, on the question of forced sterilisation, which is often picked up by proTibetan support groups in the West, Barnett recommends caution, since such practices have been verified only in certain Tibetan areas lying outside the Tibet Autonomous Region (TAR).
The third part is devoted to the Dalai Lama and Chinese policy in this regard. The main point to emerge is that China has not changed its attitude towards the Dalai Lama over the years, but it should be noted in passing that the tone of the Chinese tract is more restrained than the outburst of hatred from Chinese leaders and media after the Tibetan leader was awarded the Nobel Peace Prize in 1989, a fiery rhetoric that has been taken up with a renewed vigour since March 2008.

The Chinese pamphlet also dealt with the thorny question of demography, which enables the book's writers to further develop their thinking about the number of victims that can be attributed to China's incorporation of Tibet in the 1950s, as well as to broach the subject of population transfers (in the period 1950-1960) and economic migration (from the 1990s). Basing his work on official Chinese statistics, A. M. Fischer shows that available figures do not conclusively support the hypothesis that a million Tibetans (that is, 20 percent of the Tibetan population) died as victims of the invasion/liberation in the 1950s - the view of Dharamsala, which was contested a few years ago by Patrick French in Tibet, Tibet (Knopf, NY, 2003). However, using Chinese demographic statistics, Fischer analyses the development of the Tibetan population in Qinghai Province (that is, a large part of the inhabitants of the former traditional Tibetan province of Amdo), for which figures are available from 1952 onwards. He shows on the one hand (p. 137) that the Tibetan population there grew more slowly between 1952 and $1978(+48 \%)$ than did the Muslim population over the same period in this same province $(+93 \%)$, and also more slowly than the Chinese population overall $(+73 \%$ between 1953 and 1982). Fischer attributes this phenomenon to "the excessive loss of human life during the peaks of violence and famine in the Tibetan areas between the mid-1950s and 1962" (ibid.). For the period 1957-1963, he goes on to show (pp. 143-144) that the Tibetan population in Qinghai dropped by 20 percent, as against 5 percent for the total population of China (the Great Leap Forward being a major cause of this decrease). The anti-Communist revolt that ignited Amdo in 1958 and the famine caused by the Great Leap Forward (1958-1960) are the main explanations advanced for this figure. Fischer is careful not to extend his conclusions to the whole of the Tibetan areas of China, for which comparable data is lacking, but the fact remains that he provides the first precise, irrefutable, and overwhelming figures on this subject.

As to the relocation of the Chinese population to "greater Tibet," Fischer observes that it mainly occurred in the peri- 
(ת)

od 1950-1960 and did not last long due to the hardships encountered. Whilst non-Tibetan migration remained moderate in the countryside and pastoral areas, Fischer shows that it became more marked in the cities from the mid-1990s onwards, and especially from 2000. That was the year in which the Xibu da kaifa campaign (the opening up of the Western regions) was launched, supposedly to enable areas that were sparsely populated (and populated especially by "national minorities"), inhospitable, and relatively poor, to take off economically thanks to the arrival en masse of nonnative people. Fischer raises an important point not previously highlighted, which is that whatever their number, Han and Muslim Chinese who settled in the western cities enjoyed an advantage in snaring available commercial opportunities due to language and inland networks, and elbowed out Tibetans in the race to urbanisation and modernisation (p. 151).

One important and recurrent bone of contention for Tibetans is the impediment to the freedom of worship, and the subject of "religious belief" makes up the fifth part of the work (ten questions out of the hundred). A.-M. Blondeau, who is responsible for the whole set of answers here, shows that the complacent tone of the Chinese answers stems mainly from the formulation of the questions, which omitted less consensual aspects of the situation. These include the successive campaigns of political and patriotic re-education imposed on monks and nuns since 1996, during which they were obliged, inter alia, to disavow the Dalai Lama and proclaim Tibet to be part of China; the restrictive conditions for admission into the monasteries; and the increasingly political role of the administrative committees of the monasteries, which were set up in 1959. Blondeau also takes note of the public financing of monastery restoration, demonstrating that it has targeted only a few spectacular tourist projects, to the detriment of more modest places of worship ravaged by the Cultural Revolution, the reconstruction of which was left to the generosity of individuals. She observes in passing that the official tract makes only brief mention of the Cultural Revolution, with no specific reference to Tibet. This seems to be the rhetoric currently adopted by China, which serves a dual purpose. On the one hand, it minimises the real disaster wrought by the "destruction of the four olds" (a slogan of the Cultural Revolution) among the Tibetan people, who were at the time and are still today deeply attached to religion and traditions. On the other hand, it avoids turning Tibet into a special case, and thereby giving comfort to the idea that Tibet is not China.

The next chapter is devoted to the question of autonomy, a

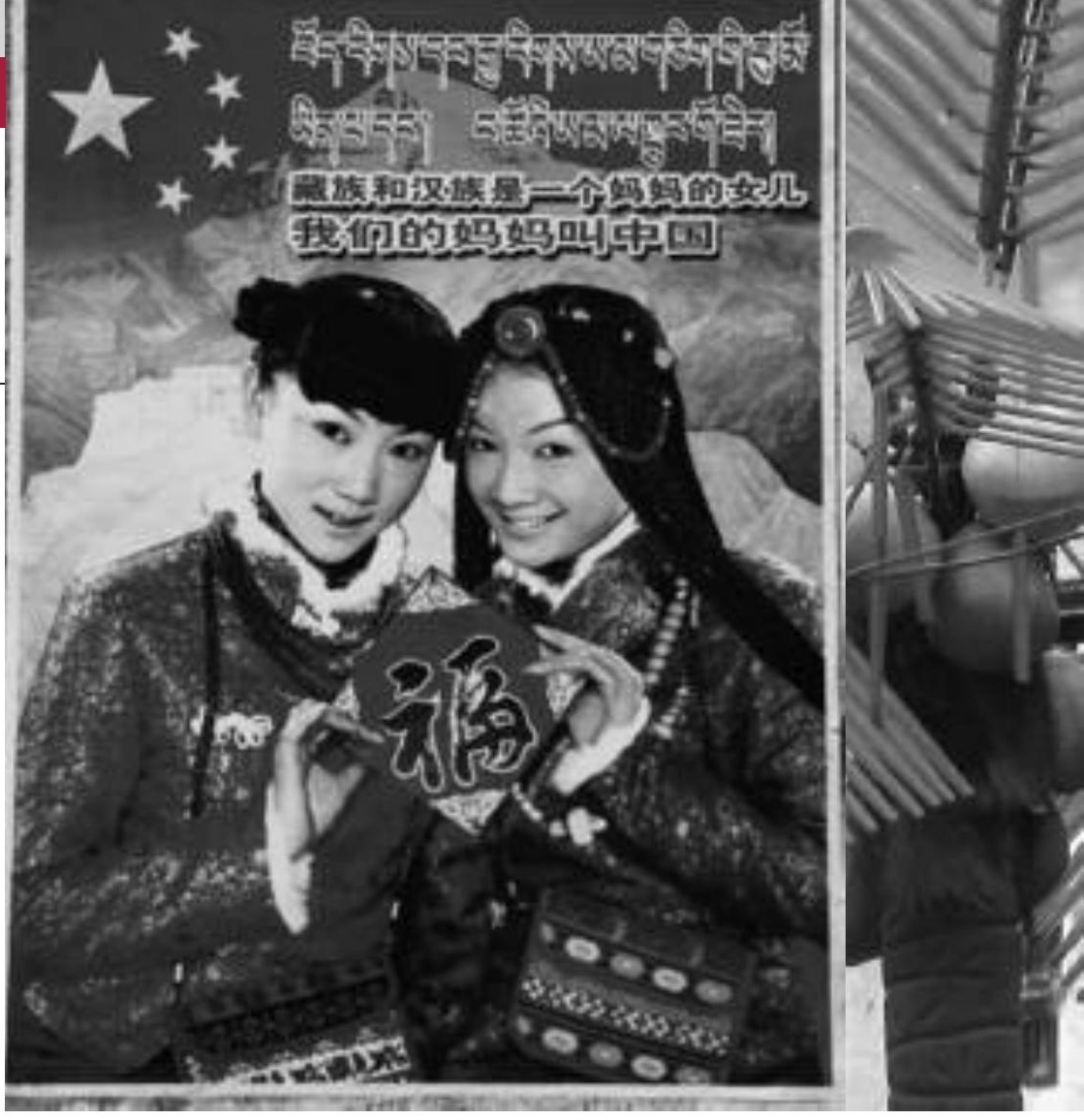

point of friction between China and the Tibetan government in exile. Indeed, China deems the question to have been settled, since all of the areas where the Tibetan population is in the majority are under a special, so-called autonomous administrative regime, be it regional (the Tibet Autonomous Region), prefectoral (the 11 Tibetan autonomous prefectures in the neighbouring Chinese provinces of Qinghai, Gansu, Sichuan, and Yunnan), or district (there are two Tibetan autonomous districts). This status, granted to other "national minorities" forming the majority in any given administrative division, theoretically allows the population in question to enjoy a certain freedom in the implementation of policies, particularly in terms of education, culture, and the economy, and it enforces a policy of affirmative action in administration that favours these "national minorities" (which are in this case the majority).

However, as revealed by T. Dodin (University of Bonn), one of the authors of the responses, a close reading of statistics provides a less rosy view of the autonomy enjoyed by these territories: the percentage of Tibetan state employees in the TAR has recently undergone a massive reduction (rising from nearly 63 percent in 1989 to 72 percent in 2000 but dropping back to under 50 percent in 2003) and is well below the proportion (92 percent) of Tibetans officially resident in the TAR (p. 202). What is more, the Communist Party and the army are not required to apply affirmative action policies, and the low proportion of Tibetans (22 percent) within the Chinese Communist Party of the TAR makes it difficult to assert that Tibetan views are well represented. And as we know, the Chinese Communist Party also presides over state administrations such as culture, health, education, and justice, and various organisations such as the 
The Potala under

palm trees.

() Françoise Robin

Tibet and a Norwegian university, enables one to maintain a certain level of optimism.

The economy is dealt with in chapter 8 , with A. Fischer showing that the central government's considerable investment in Tibet has brought little benefit to Tibetans. Indeed, these investments, decided in the context of an urban and centralised policy in which Tibetan cadres had barely any say, have not been adapted to the socio-economic reality of Tibet, which is still largely rural (nearly 90 percent of Tibetans work in agriculture and herding). The positive impact that major investment could have had on the local population has been counteracted by government infrastructure imposing real estate projects that are essentially urban, and the development of transport axes (including the spectacular rail network linking Lhasa to several provincial capitals) to the detriment of secondary road networks that would

Youth League and the Federation of Women, which are not without power.

Culture and education are at the core of chapter 9. The Chinese government often promotes Tibetan culture, and is increasingly wont to do so with the development of tourism (which quadrupled from one million visitors in 2004 to four million in 2007). Support for publication of the epic of Gesar, a literary and cultural monument in Tibet, for Tibetan opera, and the art of the thangka (portable religious representations often painted on cloth), as well as for architectural heritage and medicine, are among the areas in which the Chinese government considers it has shown its concern for protection and development. A.-M. Blondeau and A. Heller (CNRS), as well as F. Meyer (EPHE) for medicine, show that while such expressions of Tibetan culture have benefited to some extent from the attention given by the Chinese authorities, the state has often tried to secularise festivals, celebrations, and representations that in times past were endowed with religious significance. The famous "Horse Festival" of Jyekundo (Yushul, Qinghai), which attracts thousands of visitors not only from China but also from across the world to celebrate the equestrian feats and agility of Tibetans, has been partially emptied of its religious content - prior to 1950, people used such occasions to pay tribute to local divinities. When it comes to heritage, it is true that Potala Palace has been the subject of many renovations; but Heller points out that the renovations are generally piecemeal and of very poor quality, and that the old city of Lhasa has suffered from poorly planned urban development and the vagaries of changing policies. However, the conference held in 2004 on the conservation of architecture and murals in Tibet, jointly organised by the University of have benefited the local economy. On the other hand, as elsewhere in China, the gradual withdrawal of the state from the sectors of education and health weigh heavily on those with the lowest incomes, in this case the nomadic farm workers and monks of Tibet. China's professed philanthropy is also tempered by the substantial benefits it reaps from the exploitation of Tibet's natural resources (water, flora and fauna, forests, and minerals).

The favourable policy towards migrants to the TAR beginning in 1992, and followed by the Xibu da kaifa campaign, resulted in a concentration of resources and businesses in the hands of the Han and Hui ethnic groups, whose networks and knowledge of Chinese allow them to more quickly and effectively develop small local businesses. Continuing in the next chapter to consider the TAR's relatively poor economic development, Fischer shows that income disparity, a matter that worries the Chinese government because of the tensions it causes, is even worse in the TAR than in the rest of China. Thus, the growth rate, which has for some years been higher in the TAR than in China proper, masks a growing discrepancy in income among city dwellers (Lhasa's poverty rate of 11 percent is the third highest in China, while its average income ranks seventh in the country - p. 300) and between urban and rural dwellers; the urban-rural differential was closer to the national average in the mid-1990s, but in 2001 it was the greatest in all China, with incomes 5.6 times higher in the cities than in the countryside, as against 2.9 on average in China (p. 301).

The vexed question of slavery and bondage, customs and festivals, is treated in the penultimate chapter, entitled "Livelihood of the People." K. Buffetrille, complementing the responses given by R. Barnett on the same subject 
(question 19), offers insight into the social structures of pre1950 Tibet that is of particular value, given that the Chinese justified the 1950 invasion/liberation of Tibet based partially on this situation. Whilst "ancient" Tibet was by no measure an earthly paradise, as some enthusiasts and zealots of the Tibetan cause would suggest, the social relations prevailing then cannot be reduced to a caricature of cruel masters (the "three feudal lords" of the Tibetan government, the aristocracy, and the monasteries) with the power of life and death over their slaves or serfs, terms that should be used with caution. This chapter carries on with a debate over the poverty of Tibetans. The questions on customs and festivals, jointly written with J. Gyatso (Harvard), provide a glimpse into the richness of Tibetan tradition.

The final chapter, grouping ten of the hundred questions that originally made up the white paper, is devoted to the Lhasa demonstrations of 1989. It is interesting to see that the second version of the white paper eliminated nine of these questions, but the editors of the present work had the good sense to retain them, and readers will find answers here that are particularly welcome in the light of current events. In fact, one can see, nearly 20 years earlier, the same discourse incriminating "a handful of separatists," the "Dalai Lama clique," and the four-pronged "destruction, sabotage, looting, and burning" that was revived in the Chinese press in 2008 to characterise the criminal acts of the rioters in Lhasa. As in 1989, the Chinese government seems incapable of self-criticism regarding its policy of intensive and China-centred development in Tibet (the only two concessions, regarding the arrests of innocent people and errors imputable to the Cultural Revolution, having been omitted from the second Chinese version). One may anticipate that a third edition of the Chinese tract, if it ever appears, will contain a chapter on the demonstrations of March-April 2008. Indeed, their scope and perhaps their international impact have far exceeded those of nearly 20 years ago, which were essentially confined to Lhasa, and for which the means of information available at the time (or rather that were not available: internet, mobile phone, SMS), deprived them of the international coverage they received this year.

This is a very commendable work indeed. It is nonetheless not devoid of faults. For example, it would have been worthwhile to devote more space to the fundamental questions of Tibetan language and education, even if the Chinese tract includes only a few questions on the subject (a telling omission in itself). It would have been worth pointing out the curious absence of any secondary school in the Tibet Autonomous Region using Tibetan as the language of instruction. ${ }^{(1)}$ In addition, an exploration of the network of neidi classes and schools throughout inland China that receive secondary school and higher education students from the TAR would have been welcome. These classes and institutes of learning, reserved for the best Tibetan primary school pupils from the TAR, provide secondary and tertiary studies in Chinese by Chinese teachers. This system, which has been operating since 1985, has now trained more than 25,000 young Tibetans. In their reply to question 75 (p. 236), A.-M. Blondeau and A. Heller describe the opening of such classes as an attempt to remedy the massive illiteracy of Tibetans, which is the highest in all of China, but this reveals a certain misconception as to how these schools (or classes) function. An article casting light on this subject, published by two Chinese researchers in 2003, ${ }^{(2)}$ showed that, out of the 40 to 41 weekly hours of classes in the first three years of junior secondary school, only six are devoted to the Tibetan language. ${ }^{(3)}$ The article further indicates that these students are not meant to return home during the seven to 12 years of their schooling, or to mix with other Tibetans who might reside in the same city as them (p. 100). On the subject of this new elite, illiterate in its own mother tongue, we now have two new sources, both of which appeared too late to be referenced by contributors to Authenticating Tibet, but which are worth mentioning here. ${ }^{(4)}$

The second criticism relates to the geographical coverage of "Tibet." As the events of March 2008 have clearly demonstrated, the presence of Tibetans, far from being confined to the TAR alone, is massive in vast areas of the provinces of Qinghai, Gansu, Sichuan, and, to a much lesser extent, Yunnan. This reality, whilst known to specialists, has long remained invisible to the general public, whether Chinese or Western. However, most contacts, studies, and fieldwork on which scholars of Tibet have been relying for more than 20 years tend to focus on the TAR to the detriment of Amdo

1. "Tibetan language teaching at primary level was introduced in 1985. It was meant to have been followed by the gradual introduction of Tibetan language at the secondary level, but this was never implemented. [...] In 1996, projects to develop the teaching of Tibetan language at the secondary level were abandoned." Catriona Bass, "Le développement de l'enseignement", in Action poétique, n 157, Winter 1999, p. 72 and 74 (editor's translation). For a review of education policies in the TAR since 1950, see Catriona Bass, Education in Tibet. Policy and Practice since 1950, London, Zed books, 1998.

2. Wang Chengzhi and Zhou Quanhou, "Minority Education in China : From StatePreferential Policies to Dislocated Tibetan Schools ", Educational Studies, vol. 29, n 1 , p. $85-104$

3. Ibid., table VI, p. 101.

4. Zhu Zhiyong, State Schooling and Ethnic Identity. The Politics of a Tibetan Neidi Secondary School in China, Lanham, Lexington Books, 2007 ; Educational Review, vol. $60, n^{\circ} 1,2008$, «Special Issue : Education of Tibetans ». 
and Kham, and the responses in this book likewise mainly concern the TAR. Thus, there is still a lack of clarity about education policies outside of the TAR, where there are, in fact, junior and senior secondary schools operating with Tibetan as the language of instruction. The same observation can be made in relation to other subjects, such as the question of autonomy, the economy, or culture. The rich and detailed contribution by F. Meyer on the development of medicine in Tibet since 1950 would have gained from taking account of the medical colleges of Xining (Qinghai), Dzorge and Tsö (Gansu), for example, as well as the many publications that have come out of these provinces.

Finally, more maps would have been very welcome, particularly to illustrate the part concerned with history, which readers unfamiliar with the mountainous regions of Central Asia are likely to find hard going. The original French version also included a photo album, and it is a pity that the American publisher did not think it worthwhile to reproduce this.

We will conclude with two wishes. The first is for Chinese and Tibetan scholars in China to publish a third version, also brought up to date, but with as much material and detail - and therefore as demanding and rigorous - as Authenticating Tibet. Secondly, it would be very worthwhile for a Chinese publisher to translate this current volume, as it gives a number of new insights, both indispensable and serious, into the "Tibetan question," which, as recent events have shown, is far from being settled. Whilst Westerners have access to a range of voices and contrasting views (albeit overwhelmingly sympathetic) on the Tibetan problem, Chinese citizens are often forced to rely largely on the Chinese media, which in the great majority of cases is subject to censorship and self-censorship. The events in Lhasa in 2008 have given rise to a few measured opinions in some progressive media. These have been quickly called to order, however, as the limit of tolerance in the treatment of Tibetan affairs seems to be more quickly reached than on other subjects. At the same time, the media, in particular the Internet, have been inundated with a chorus of peremptory, nationalistic, and highly unsympathetic reactions to the Tibetan question. It is urgent that on this point (as on others) Chinese citizens should have access to less impassioned and more substantiated information, to prevent a radicalisation of tensions between Hans and Tibetans in China. If this book is published in Hong Kong or Taiwan, it will quickly reach the book market in the People's Republic of China through backdoor channels. It could then contribute to initiating the questioning of a good many assumptions.

\section{- Translated by Peter Brown}

